\title{
PSYCHOLOGICAL WELL-BEING AND SPIRITUAL INTELLIGENCE AS PREDICTORS OF SUICIDAL IDEATION AMONG EMERGING ADULTS IN MALAYSIA
}

\author{
Foo Suh Jin ${ }^{1}$ \\ Faculty of Arts and Social Sciences, Universiti Tunku Abdul Rahman (UTAR), Malaysia. \\ (Email: suhjin@1utar.my) \\ Lo Kah Wah ${ }^{2}$ \\ Faculty of Arts and Social Sciences, Universiti Tunku Abdul Rahman (UTAR), Malaysia. \\ (Email: advenlkw93@1utar.my) \\ Wirawahida Kamarul Zaman ${ }^{3}$ \\ Faculty of Arts and Social Sciences, Universiti Tunku Abdul Rahman (UTAR), Malaysia. \\ (Email: wirawahida@utar.edu.my) \\ Sanggari Krishnan ${ }^{4}$ \\ Faculty of Arts and Social Sciences, Universiti Tunku Abdul Rahman (UTAR), Malaysia. \\ (Email: sanggari@utar.edu.my) \\ Komathi Lokithasan ${ }^{5}$ \\ Faculty of Arts and Social Sciences, Universiti Tunku Abdul Rahman (UTAR), Malaysia.
} (Email: komathil@utar.edu.my)

Received date: 11-06-2019

Revised date: 16-06-2019

Accepted date: 11-09-2019

Published date: 15-09-2019

To cite this document: Foo. S. J., Lo, K. W., Kamazul Zaman, W., Krishnan, S., \& Lokithasan, K. (2019). International Journal of Education, Psychology and Counseling, 4 (32), 139-148. DOI: $10.35631 / \mathrm{IJEPC} .4320014$

\begin{abstract}
Suicide behavior is one of a worrisome issue not only in Malaysia but all over the world. The World Population Review and Statista in 2019 reported suicide case in Malaysia was 5.5 per 100,000 inhabitants in 2016 and showed an increasing pattern for the past three years $(W H O, 2018)$ revealed that most of the suicide cases lead to mortality were came from the age of 15 to 29 years old. The current study aims to explore the suicidal ideation issue of emerging adults between the age of 18 to 25 years old. During this period, they may face many challenges such as searching for self-identity, instabilities of life, and sudden loss of life direction due to no or few obligation and commitment to others, which may have an impact towards their psychological health (Eccles, Templeton, Barber, \& Stone, 2003). Therefore, the objective of this study is to identify the relationship between psychological well-being and spiritual intelligence and suicidal ideation among emerging adults in Malaysia. A total of 304 samples were recruited, but only 271 samples had completed the questionnaires, which was collected through the online and paper-and-pencil method. The Scale of Suicidal Ideation (SSI), Ryff's Psychological Well-Being Scale-42 items, and Spiritual Intelligence Self-Report Inventory-24 items were used to measure all variables in this study. Data collected was
\end{abstract}


calculated using the Statistical Package for Social Science (SPSS) software version 25.0. Results of Pearson correlation showed that there was a significant negative correlation between psychological well-being and suicidal ideation while a significant positive correlation between spiritual intelligence and suicidal ideation. Results of multiple linear regression found out psychological well-being, and spiritual intelligence statistically predicted suicidal ideation. Spiritual intelligence is the best predictor to suicidal ideation. Implications and limitations of this study were discussed, and recommendations for future studies were made.

Keywords: Suicidal Ideation, Psychological Well-Being, Spiritual Intelligence, Emerging Adulthood

\section{Introduction}

According to World Health Organization (WHO, 2018), around 8 million of people die each year due to suicide, the most of the suicide cases lead to mortality were came from the age between 15 to 29 years old. In Malaysia, publicity director of Befriender's Kuala Lumpur, Ardy Ayadali mentioned that youth is high risk at suicidal tendency because it had been found that suicide is the second major cause of death for youth in Malaysia (New Strait Times, May 28, 2017). The newspaper also reported that Befriender's Kuala Lumpur received 24,821 of call and $30 \%$ of the callers, 7,446 were having suicidal ideation. Suicidal ideation is served as one of the signs of the suicide behaviors, especially population in the age between 15 to 29 years old.

The finding by Takwin and Atmini (2017) provide an insight into the researchers that psychological well-being plays a role in the formation of suicidal ideation. Psychological wellbeing serves as a crucial aspect of an individual to achieve his or her potential and live a satisfying life. Low psychological well-being may lead one to feel dissatisfied with self, encounter relationship issue with others, lack of the sense of purpose in life, lack of sense of control of the external environment and sense of personal stagnation (Ryff \& Singer, 1996). Psychological well-being was found to be one of the predictors of suicidal ideation of individual who attempted suicide (Jayervand, Ahdi, Mazaheri, Talebi, \& Manshaee, 2013).

Furthermore, Malaysia is a conservative society (Global Affairs Canada, 2018), which spirituality plays an essential aspect of the country. Talking about death and suicide, acquiescently is considered a taboo in Malaysia. Thus, limited research on the suicide-related topic is one of the consequences of the conservative culture in Malaysia context (Ibrahim et al., 2014).

The finding of this study can help to understand the suicidal ideation among emerging adults in Malaysia to complement the deficiency of suicidal ideation research among emerging adults. Most of the researchers are more interested in suicidal ideation cases among mental health patients, victims who survive a suicide attempt, and adolescents. Moreover, the negative perception of Malaysian in discussing death and suicide topic may indicate that Malaysian have low awareness of the seriousness of suicide cases. Thus, the finding of this study may increase the awareness of the public towards the suicidal ideation, especially emerging adulthood, to prevent severe incidents such as self-harm, suicide attempt, and committing suicide to happen.

The primary objectives of this research are to identify the relationship between psychological well-being and spiritual intelligence toward suicidal ideation among emerging adults in 
Malaysia. Also, to identify the relationship between spiritual intelligence and suicidal ideation among emerging adults in Malaysia. Other than that, this study also aims to identify the predictor of suicidal ideation among emerging adults in Malaysia.

\section{Literature Review}

The Three-Step Theory (3ST) is a new theory proposed by Klonsky and May (2015) based on "Ideation-to-Action" framework to conceptualize the formation of suicidal ideation and the transition from suicidal ideation into a suicide attempt. There are three steps of an individual to engage in a suicide attempt which started from the development of suicidal ideation, followed by second step: strong versus moderate ideation; and lastly, the progression from ideation to attempts (Klonsky, Saffer, \& Bryan, 2017). Psychological well-being is playing an essential part of human life. Several psychological issues, such as depression, anxiety (Liu et al., 2009; Ramkisson et al., 2016) and stress (Anushri et al., 2014) were found to be associated with psychological well-being. Besides, it is also found that university students in Malaysia tend to have stress issues (Jia \& Loo, 2018; Othman et al., 2013), anxiety as well as depression (Choon et al., 2015; Shamsuddin et al., 2013) which these psychological issues are determined to be correlated with suicidal ideation (Ibrahim et al., 2014).

A positive faith of spiritual showed a significant result during hardship in a lifetime; for instance, the presentation of suicide ideation (Francis \& Bance, 2017). According to Lytle, Blosnich, De Luca, and Brownson (2018), spirituality or religious were found to have a significant influence on suicide ideation among young people with a heterosexual orientation.

In a study by Francis and Bance (2017), stated that the role of spirituality as a significant factor in reducing suicidal ideation by providing the feeling of tranquility. However, Lusk, Dobscha, Kopacz, Ritchie, and Ono (2017) revealed that spirituality could daunt and permit suicide as the reasons of the suicide behaviour is restricted from a religious side, on the other hand, there is a belief of no difference between life and afterlife.

Spiritual well-being proved to have a significant correlation with suicidal ideation in some of the studies, but there are limited research done to study spiritual intelligence as the predictor to suicidal ideation although researches indicated that spirituality plays a role in suicidal ideation over the past decade years.

Thus the researchers are interested in the relationship between psychological well-being, spiritual intelligent and suicidal ideation among emerging adult in Malaysia since this population may expose to high stress that may affect their psychological well-being and spiritual intelligence. Hence, it may lead to suicidal ideation.

\section{Methodology}

This current research employed a quantitative research method with a cross-sectional study to investigate the relationship between psychological well-being, spiritual intelligence, and suicidal ideation. Three instruments were used to measure the variables in the study; The Scale of Suicidal Ideation (SSI), Ryff's Psychological Well-Being Scale-42 items and Spiritual Intelligence Self-Report Inventory (SISRI-24). The purposive sampling method is utilized in this research with the age range between 18 to 25 years old as the inclusion criteria.

According to the Malaysia demographics profile in 2018 revealed that there are approximately $5,210,792$ of 18 to 25-year-old emerging adults in Malaysia. G-power was used to generate the 
sampling size. Based on the Gpower calculation, the sample size that is needed to run multiple linear regression in this study was 107 samples. However, in the actual study, 304 sets of questionnaires were distributed, but only 271 samples completed the questionnaires. A total of 271 participants from 18 to 25 years old $(M=21.10, S D=2.14)$ were involved in this study as shown in Table 4.1

Table 4.1: Demographics of Respondents

\begin{tabular}{|c|c|c|}
\hline $\begin{array}{l}\text { Demographic } \\
\text { profile }\end{array}$ & Frequency & Percentage $(\%)$ \\
\hline \multicolumn{3}{|l|}{ Age } \\
\hline 18 & 49 & 18.1 \\
\hline 19 & 16 & 5.9 \\
\hline 20 & 48 & 17.7 \\
\hline 21 & 39 & 14.4 \\
\hline 22 & 49 & 18.1 \\
\hline 23 & 18 & 6.6 \\
\hline 24 & 38 & 14.0 \\
\hline 25 & 14 & 5.2 \\
\hline
\end{tabular}

Gender

$\begin{array}{lll}\text { Male } & 104 & 38.4 \\ \text { Female } & 167 & 61.6\end{array}$

Ethnicity

$\begin{array}{lcc}\text { Malay } & 23 & 8.5 \\ \text { Chinese } & 225 & 83.0 \\ \text { Indian } & 15 & 5.5 \\ \text { Others } & 8 & 3.0\end{array}$

Data was collected through a paper-and-pencil and online method. Informed consent is attached to the four-section questionnaire. The questionnaire consisted of 85 items, and it was estimated to take approximately 15 to 20 minutes for participants to complete it.

The Pearson Correlation analysis was used to calculate the relationship between psychological well-being, spiritual intelligence, and suicidal ideation among emerging adulthood in Malaysia, 
while Multiple Regression is used to find the predictor to suicidal ideation. Cronbach's coefficient for all the instruments was shown in Table 4.2.

Table 4.2: Reliability of the Instrument

\begin{tabular}{|c|c|c|c|c|}
\hline \multirow[b]{2}{*}{ Variable } & \multirow{2}{*}{$\begin{array}{l}\text { No. of } \\
\text { Items }\end{array}$} & \multicolumn{3}{|c|}{ Cronbach Alpha } \\
\hline & & Past Study & Pilot Study & Actual Study \\
\hline $\begin{array}{l}\text { The Scale of Suicidal ideation } \\
\text { (SSI) }\end{array}$ & 19 & $.84-.93$ & .88 & .96 \\
\hline $\begin{array}{l}\text { Ryff's Psychological Well- } \\
\text { Being Scale-42 item }\end{array}$ & 42 & $.86-.93$ & .91 & .91 \\
\hline $\begin{array}{l}\text { Spiritual Intelligence } \\
\text { Report Inventory-24 } \\
\text { (SISRI-24) }\end{array}$ & 24 & .95 & .87 & .91 \\
\hline
\end{tabular}

\section{Findings}

\section{Frequency Distribution}

The mean score for all variables was shown in Table 4.3. The mean score for total suicide ideation for the participants in this study is 12.61 ( $\mathrm{SD}=11.22$ ). The mean score for total scores of psychological well-being and total scores of spiritual intelligence is 166 (SD =26.82) and $63.12(\mathrm{SD}=14.16)$ respectively.

Table 4.3: Frequencies Distribution of Suicide Ideation, Psychological Well-Being and Spiritual Intelligence $(\mathbf{N}=\mathbf{2 7 1})$

\begin{tabular}{llccc}
\hline Variable & M & SD & Min & Max \\
\hline Suicidal Ideation & 12.61 & 11.22 & 0 & 47 \\
Psychological Well-being & 166.00 & 26.82 & 87 & 297 \\
Spiritual Intelligence & 63.12 & 14.16 & 23 & 115 \\
\hline
\end{tabular}

Note. M: Mean; SD: Standard Deviation; Min: Minimum Score; Max: Maximum Score

Correlation Analysis between Psychological Well-being, Spiritual Intelligence, and Suicidal Ideation

The results of Pearson correlation showed that there is a significant negative correlation between psychological well-being and suicidal ideation among emerging adults in Malaysia, $\mathrm{r}(271)=-.337, \mathrm{p}<.001$. This result indicated that emerging adults in Malaysia who are testified to have a higher score on psychological well-being were more likely to have a lower score on suicidal ideation.

Fascinatingly, there is a significant positive correlation between spiritual intelligence and suicidal ideation among emerging adults in Malaysia, $\mathrm{r}(271)=.351, \mathrm{p}<.001$. The result 
illustrates that the higher the score on spiritual intelligence among emerging adults in Malaysia, the higher the score of suicidal ideation. All the result is shown in Table 4.4

Table 4.4: Correlations among Suicidal Ideation, Psychological Well-Being, and Spiritual Intelligence

\begin{tabular}{|c|c|c|c|}
\hline Variable & 1 & 2 & 3 \\
\hline Suicidal Ideation & - & $-.337 * * *$ & $.352 * * *$ \\
\hline Psychological Well-being & & - & $.379 * * *$ \\
\hline Spiritual Intelligence & & & - \\
\hline
\end{tabular}

Note: Correlation marked with an asterisk (***) is significant at the 0.01 level (2-tailed).

\section{Multiple Regression Analysis for Psychological Well-being or Spiritual Intelligence as Predictors of Suicidal Ideation}

Multiple Regression analysis was used to test if the psychological well-being or spiritual intelligence was able to predict suicidal ideation. The model stated a statistically significant, $\mathrm{F}(2,268)=82.591, \mathrm{p}<.001$ and accounted for $37.7 \%$ of the variance. It was found that psychological well-being $(\beta=-.549, \mathrm{p}<.001)$ and spiritual intelligence $(\beta=.559, \mathrm{p}<.001)$ can predict suicidal ideation among emerging adults in Malaysia. The result of Multiple Regression is shown in Table 4.5.

Table 4.5: Multiple Regression Analysis as Psychological Well-Being and Spiritual Intelligence as Predictors for Suicidal Ideation

\begin{tabular}{|c|c|c|c|c|c|c|c|}
\hline Outcome & Predictor & $\mathrm{F}$ & Adj. & Df & $\bar{\beta}$ & $\mathrm{t}$ & $\mathrm{p}$ \\
\hline Variable & Variable & & $\mathrm{R}^{2}$ & & & & \\
\hline \multirow{3}{*}{$\begin{array}{l}\text { Model } \\
\text { Suicidal } \\
\text { Ideation }\end{array}$} & Psychological & 82.591 & .377 & 2,268 & $-.549 * * *$ & -10.571 & .001 \\
\hline & Well-being & & & & & & \\
\hline & $\begin{array}{l}\text { Spiritual } \\
\text { Intelligence }\end{array}$ & & & & $-.559 * * *$ & 10.768 & .001 \\
\hline
\end{tabular}

(Multiple Regression Is Significant at The 0.01 Level (2-tailed).

\section{Discussion}

The results shows a significant correlation between psychological well-being and suicidal ideation among emerging adults in Malaysia where low psychological well-being are having higher possibility to develop suicide ideation. This is consistent with the research done by Takwin and Atmini (2017) and Jayervand et al. (2013). Jayervand et al. (2013) found that when a person having low psychological wellbeing there is a high tendency to have suicidal ideation. This is because life satisfaction is essential element for healthy psychological well-being (Ryff \& Keyes, 1995). According to Klonsky and May (2015), connectedness plays an essential character in preventing suicidal thoughts. Lower psychological well-being indicated a person may be suffering from daily life challenges, such as loss of life meaning, having interpersonal issues, dissatisfaction in career and others. This means the person may vulnerable to suicidal thoughts. 
Besides that, a research done by Jin and Zhang (1998) in China also support that psychological well-being may be a predictor for suicidal ideation. Jin and Zhang (1998) explain that selfesteem is part of the psychological well-being that prevent an individual from forming suicide ideation. The forming of suicide ideation may affect by the psychological well-being. Hence, the previous studies support the finding of this study that psychological well-being has negative impact toward suicide ideation.

There is a positive correlation between spiritual intelligence and suicidal ideation in this study which is inconsistent with majority findings that indicated the higher the spiritual intelligence, the lower the suicidal ideation or vice versa. However, there were researchers found that the traditional religiosity has a slight correlation with lower levels of suicidal ideation (Robbins \& Francis, 2009). In the conservative context of Malaysia (Global Affairs Canada, 2018), spirituality and spiritual intelligence is still not well-known, most of the respondents probably believed that there is no difference between religion and spiritual intelligence especially in Eastern countries which behold the belief of spiritual intelligence is the intimacy of oneself to God (Hanefar, Sa'ari, \& Siraj, 2016), this phenomena is able to apply as a fundamental reason to explain the result of spiritual intelligence has a positive correlation with suicidal ideation.

Due to the reason of majority religion encourage followers to have religious participation such as praying which is also known as one way communication, study proved that some of the religion discourage followers to seek mental health assistance from professionals (Blank, Mahmood, Fox, \& Guterbock, 2002) as they resist to share problems with third party other than God. Those who considered religious as main part of life and attended religious related services frequently were found to have greater suicide ideation according to Lawrence et al. (2016).

The spiritual intelligence predicted on suicidal ideation was adapted by the research done by Dowlatabadi, Boland, and Saadat (2015) suggested that people in this modern era are emphasis on material world and the state of lacking ethical standards such as suicide, crime or divorce rather than spiritual aspect. In spiritual intelligence and religious aspect, Zhang and Jin (1996) also indicated that student in China, who hold the belief of religious were having suicidal thought and possessed pro-suicide attitudes. According to the study of Lester (1998) people who has the ideation for suicide is looking for the spirituality, God, meaning of life as well as for rebirth. In a nutshell, spiritual intelligence does bring the impact on suicidal ideation.

\section{Conclusion}

Suicide is one of a global concerning issue which around 8 million of people died every year (WHO, 2018). Emerging adulthood is a transitional period which they may encounter with many life challenging event which may be vulnerable to suicide related activities. Therefore, the main purpose of this research was to understand the relationship between psychological well-being and spiritual intelligence with suicidal ideation among emerging adults in Malaysia.

The finding of the study revealed that psychological well-being and spiritual intelligence are the significant predictors for suicidal ideation. Psychological well-being become a key role to prevent the formation of suicidal ideation and suicide attempt. People who are having dissatisfaction in their life are more likely to develop suicidal ideation. Spiritual intelligence was found to have a positive associated with suicidal ideation. Strong religion believers have high tendency to have suicidal ideation. 
The Three-Step Theory (3ST) is the theory imply in this research which theoritherised how suicidal ideation is form (Klonsky \& May, 2015). According to the finding of this study, it showed that psychological well-being can predict the formation of suicidal ideation. This can be explained by the theory that connectedness is the protective factor of suicidal ideation. Connectedness, in this context is define as the attachment of a person with his or her own life, such as sense of meaning in life, job satisfaction, social role and social relationship with others which can be categorized under psychological well-being. When psychological well-being is disrupted, psychological and emotional pain may increase and it also give a significant impact for the person connectedness. This situation may cause the individual become vulnerable to suicide attempt because of higher possibility to develop suicide ideation. On the other hand, a person with high psychological well-being tend to have strong connectedness which is important to cope with life challenges and prevent them from risking in suicide attempt.

In addition, strong religion believers may sometime find difficulty to sharing their concern and emotion to others. This is because the individual has limit ways to express their concern to reduce their emotional burden which eventually, according to 3ST theory, these emotion burden or emotion pain may be the reason of the formation of suicidal ideation. Therefore, person with high spiritual intelligence may tend to develop suicidal ideation due to the emotion burdensome.

Besides, the finding from this study provide some new insights to the suicide topic in Malaysia context which both predictors, psychological well-being and spiritual intelligence were found to be the predictors of suicidal ideation. The finding of positive impact from spiritual intelligence toward suicidal ideation which contradict with majority of the research finding was able to enrich the knowledge body of suicide related topic especially in Malaysian context.. The finding also able to strengthen the $3 \mathrm{ST}$ theory that psychological well-being plays important role in preventing suicide activities.

Nevertheless, the findings of psychological well-being and spiritual intelligence were still in limited quantity in Malaysia, hence, this study enhances the importance of the role of psychological well-being and spiritual intelligence influence suicidal ideation in Malaysia. Moreover, this study also encourage institutions to develop more concern on mental health or well-being of the students rather than focus on the grade and score from kindergarten to universities. This study also contribute to government sector to provide sponsors for researchers who need funds or resources to explore more on these topics because this study topic is still new in our country. Besides that, this study provides evidence for related authorities as well as public to put more efforts on concerning suicidal topics by conducting more prevention talks or campaigns to raise the awareness of young adults in Malaysia.

\section{Limitations}

This study used self-report questionnaire which was fully answered by respondents, so the accuracy of their answers may not fully attended. Using interview method to obtain the data can help the researchers to further understand the samples especially the topic related to suicide which is view as taboo in Malaysia. As Shaughnessy, Zechmeister, and Zechmeister (2015) suggested, interview allows greater flexibility for the researchers to gather more detail from the participants.

The causal relationship between variables may not be investigate due to the limitation of crosssectional study which only obtained the data from samples at once. It is recommending to apply longitudinal studies as it promotes develop deeper and longer understandings the impact of the 
predictors toward the outcome variables as well as the advantage to draw causal relationship from the research (Shaughnessy et al., 2015).

In addition, the study were used non-probability sampling methods (purposive sampling method and snowball sampling method) as the sampling method which may have caused bias because it does not guarantee each individual in the targeted population has equal chance to be included in sample (Shaughnessy et al., 2015). Thus, bias may affect the result to generalize the population. Probability sampling method such as simple random sampling method has the advantage to minimize the bias which may increase the accuracy of the future research to generalize the population.

\section{References}

Abdollahi, A., Talib, M. A., Yaacob, S. N., \& Ismail, Z. (2015). Problem-solving skills and suicidal ideation among Malaysian college students: The mediating role of hopelessness. Academic Psychiatry. doi:10.1007/s40596-015-0383-0

Anushri, M., Yashoda, R., \& Puranik, M. P. (2014). Relationship between psychological wellbeing and perceptions of stress among undergraduate dental students in Bengaluru city: A cross sectional study. Journal of Indian Association of Public Health Dentistry, 12(4), 283.

Begum, A. K. M., Rahman, F., Rahman, A., Soares, J., Khankeh, H. R., \& Macassa, G. (2017). Prevalence of suicidal ideation among adolescents and young adults in rural Bangladesh. International Journal of Mental Health. doi:10.1080/00207411.2017.1304074

Christensen, L. B., Johnson, R. B., \& Turner, L. A. (2014). Research methods, design, and analysis (12th ed.). Westford, MA: Pearson Education, Inc

Dowlatabadi, F. H., Boland, H., \& Saadat, S. (2015). The role of spiritual intelligence and quality of life in prediction of suicidal ideation among students at University of Guilan. International Journal of Scientific Research and Reviews, 4(3), 48-58. Retrieved from http://www.ijsrr.org/pdf/472.pdf

Emmons, R. A. (2000a). Is spirituality an intelligence? Motivation, cognition, and the psychology of ultimate concern. International Journal for the Psychology of Religion, 10(1), 3-26. doi:10.1207/s15327582ijpr1001_2

Foo, S. J., \& Lo, K. W. (2018). Psychological well-being and spiritual intelligence as predictors of suicidal ideation among emerging adults in Malaysia (Doctoral dissertation, UTAR).

Francis, W., \& Bance, L. O. J. (2017).

Protective role of spirituality from the perspective of Indian college students with suicidal ideation: "I am here because god exists". Journal of Religion and Health, 56(3), 962970. doi:10.1007/s10943-016-0296-6

Gaskin-Wasson, A. L., Walker, K. L., Shin, L. J., \& Kaslow, N. J. (2016). Spiritual well-being and psychological adjustment: Mediated by interpersonal needs? Journal of Religion \& Health, 57(4), 1376-1391. doi:10.1007/s10943-016-0275-y.

Global Affairs Canada - Affaires. "Global Affairs Canada." GAC, 21 Aug. 2019, www.international.gc.ca/gac-amc/index.aspx?lang=eng.

Hanefar, S. B., Sa'ari, C. Z., \& Siraj, S. (2016). A synthesis of spiritual intelligence themes from islamic and western philosophical perspectives. Journal of Religion and Health, 55(6), 2069-2085. doi: 10.1007/s10943-016-0226-7

Ibrahim, N., Amit, N., \& Suen, M. W. Y. (2014). Psychological factors as predictors of suicidal ideation among adolescents in Malaysia. PLoS One, 9(10), e110670. 
Jafari, E., Dehshiri, G. R., Eskandari, H., Najafi, M., Heshmati, R., \& Hoseinifar, H. (2010). Spiritual well-being and mental health in university students. Procedia-Social and Behavioral Sciences, 5, 1477-1481. doi:10.1016/j.sbspro.2010.07.311

Jayervand, H., Ahdi, H., Mazaheri, M. M., Talebi, H., \& Manshaee, Q. (2013). Prediction of suicidal ideation based on psychological well-being and religious spiritual determinants among individuals with attempted suicide. Journal of Basic and Applied Scientificc Research, 3(8), 587-590.

Kamoei, K., \& Meschi, F. (2016). The relationship between perceived stress and coping styles with psychological well-being in cardiac patients. International Journal of Medical Research and Health Sciences, 5(11), 707-711. Retrieved from https://www.ijmrhs.com/medical-research/the-relationship-between-perceived-stressand-coping-styles-with-psychological-wellbeing-in-cardiac-patients.pdf

Klonsky, E. D., Saffer, B. Y., \& Bryan, C. J. (2017). Ideation-to-action theories of suicide: A conceptual and empirical update. Current Opinion in Psychology. doi:10.1016/j.copsyc.2017.07.020

Liu, Y., Wang, Z., Zhou, C., \& Li, T. (2014). Affect and self-esteem as mediators between trait resilience and psychological adjustment. Personality and individual differences, 66, 9297.

Lusk, J., Dobscha, S. K., Kopacz, M., Ritchie, M. F., \& Ono, S. (2018). Spirituality, religion, and suicidality among veterans: A qualitative study. Archives of suicide research, 22(2), 311-326.

Lytle, M. C., Blosnich, J. R., De Luca, S. M., \& Brownson, C. (2018). Association of Religiosity with sexual minority suicide ideation and attempt. American journal of preventive medicine, 54(5), 644-651.

Ryff, C. D., \& Singer, B. (1996). Psychological well-being: Meaning, measurement, and implications for psychotherapy research. Psychotherapy and Psychosomatics, 65(1), 14-23. doi:10.1159/000289026

Shaughnessy, J. J., Zechmeister, E. B., \& Zechmeister, J. S. (2015). Research methods in psychology (10 ed.). New York: McGraw-Hill Education.

Teh, C. K., Ngo, C. W., binti Zulkifli, R. A.,Vellasamy, R., \& Suresh, K. (2015). Depression, anxiety and stress among undergraduate students: A cross sectional study. Open Journal of Epidemiology, 5(04), 260.

Vancea, F. (2014). Spiritual intelligence - Description, measurement, correlational analyses. Journal of Experiential Psychotherapy, 17(65), 33-44. Retrieved https://jep.ro/images/pdf/cuprins_reviste/65-5\%20p.\%2037-44.pdf

World Health Organization (WHO). SpringerReference. doi: 10.1007/springerreference_70205

Zhang, X., \& Wu, L. (2014). Suicidal Ideation and Substance Use among Adolescents and Young Adults: A bidirectional relation? Drug Alcohol Depend. doi:10.1016/j.drugalcdep.2014.05.02

Zarrett, N.R., \& Eccles, J.S. (2006). The passage to adulthood: challenges of late adolescence. New directions for youth development, 111, 13-28, 7 . 